p-ISSN. 2086-9029

e-ISSN. 2654-5675

Vol. 22 No. 1, Hlm. 1-158, Juni 2020

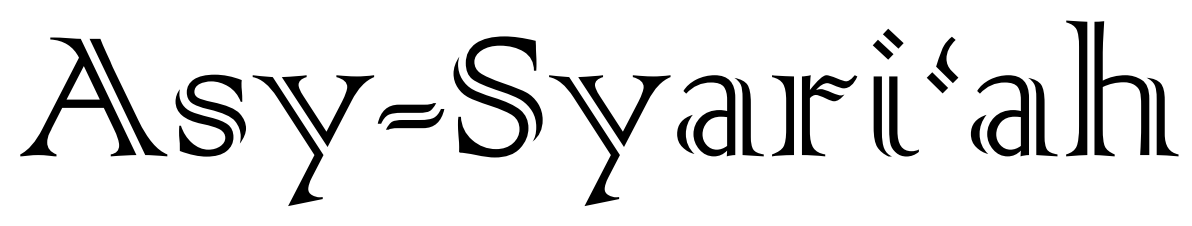

- Hukum Waris Islam Sebagai Instrumen Kepemilikan Harta

$(1-20)$ Hafidz Taqiyyudin

- Komparasi Metodologi Hukum Aliran Maqasidi dan Aliran Syakli

$(21-34)$ Hudzaifah Achmad Qotadah

- Reinterpretasi Hak Ijbar dalam Hukum Perkawinan Islam di Keluarga $(35-50)$ Pesantren

Kudrat Abdillah

- Dimensi Kondisionalitas dan Fleksibilitas Al-Quran bagi Implementasi $(51-66)$ Fatwa DSN-MUI tentang Produk Bank Syariah

Ahmad Hasan Ridwan, Asep Rahmat

- Validitas Hadis Tidak Ada Kisas bagi Orang Tua yang Membunuh Anaknya

Moh. Ahsanuddin Jauhari, Enceng Arif Faizal, Syahrul Anwar, Atep Mastur, Deden Najmudin

- Penguatan Resolusi Konflik Berbasis Tradisi Sunnah Nabi

Alamsyah

- Sistem Perencanaan, Pelaksanaan dan Pengawasan Industri Halal di Wilayah Provinsi Banten

Akhyakudin, Suja'i, Muhammad Abduh

- Reformulation of Family Legal in Indonesia for Female Maslahah

Wahidullah, Murniati, Yushinta Eka Farida, Jumaiyah

- The Concept and Aplication of Covenant in Financing Gold Pawn By Sharia Bank in West Java

Neni Nuraeni, Dewi Sulastri, Zulbaidah

- Tinjauan Sosiologi Hukum tentang Kepatuhan Masyarakat terhadap ( $147-158)$ Undang-Undang Wakaf

Deden Effendi

FACULTY OF SHARIA AND LAW

STATE ISLAMIC UNIVERSITY SUNAN GUNUNG DJATI BANDUNG-INDONESIA IN COLLABORATION WITH ASOSIASI SARJANA SYARIAH INDONESIA 


\section{Asy-Syari'ah}

Volume 22, Number 1, 2020

\section{EDITOR-IN-CHIEF}

Ine Fauzia

\section{EDITORIAL BOARD}

Sofyan al-Hakim, UIN Sunan Gunung Djati Bandung, Indonesia Deni Kamaludin Yusup, UIN Sunan Gunung Djati Bandung, Indonesia Meria Utama, Fakultas Hukum Univrsitas Sriwijaya, Indonesia Dewi Mayaningsih, UIN Sunan Gunung Djati Bandung, Indonesia Andrey Sujatmiko, Fakultas Hukum Universitas Trisakti, Jakarta, Indonesia Hetty Hassanah, Universitas Komputer Indonesia, Indonesia

\section{PEER-REVIEWERS}

Muhammad Irfan Helmy, IAIN Salatiga, Semarang, Indonesia Ahmad Ali Nurdin, UIN Sunan Gunung Djati Bandung Tajul Arifin, UIN Sunan Gunun Djati Bandung, Indonesia Mohamad Anton Athoillah, UIN Sunan Gunung Djati Bandung, Indonesia Mrs. Renny Supriyatni, Universitas Padjadjaran, Indonesia Ahmad Tholabi Karlie, UIN Syarif Hidayatullah Jakarta, Indonesia Ija Suntana, UIN Sunan Gunung Djati Bandung, Indonesia Zezen Zaenal Mutaqin, University of California, Los Angeles, United States Ahmad Fathonih, UIN Sunan Gunung Djati Bandung, Indonesia Rahman Syamsuddin, Universitas Islam Negeri Alauddin Makassar, Indonesia

\section{PROOFREADER/DESIGN COVER}

Nanang Sungkawa

\section{LAYOUT EDITOR}

Opik Rozikin

Asy-Syari' ah has been accredited based on the determination of Director General of Research and Development Strengthening, Ministry of Research, Technology and Higher Education of Republic of Indonesia, No. 14/E/KPT/2019 (valid until 2023). 


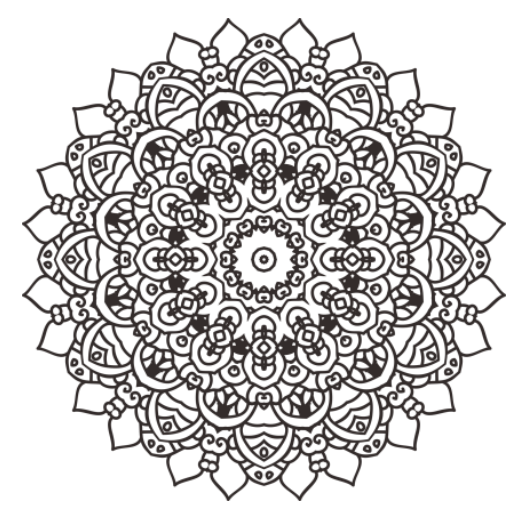

\title{
TINJAUAN SOSIOLOGI HUKUM TENTANG KEPATUHAN MASYARAKAT TERHADAP UNDANG-UNDANG WAKAF
}

\author{
Deden Effendi \\ Fakultas Syari'ah dan Hukum UIN Sunan Gunung Djati Bandung \\ E-mail: dedeneffendi@uinsgd.ac.id
}

\begin{abstract}
Waqf law can be categorized as a living law and potential of waqf can be written. The law of the living does not fully comply with regulations. This problem can lead to law-enforcement-representation issues then formulated into the question: How to advocate community against the Waqf Law? It contains public knowledge, public awareness and public obedience. Assuming sharia is natural law, it is eternal and does not change. In the case, sharia is not in accordance with waqf. The provisions of waqf law are obtained through ushul fiqh with analogical deductive reasoning patterns. The rest, the provisions regarding waqf agreement are obtained from human preferences about the general good. Waqf law is based ruh al-hukm, the spirit of teachings, and maqashid al-shariah. It is more important to be developed to be more responsive to people's priorities and needs. Opportunities for enforcement of waqf law are very large, so that at that time the community complied with waqf law. This research is a descriptive study, which analyzes waqf as a system, as well as a subsystem of a wider system. This analysis, explains the process of society from knowledge to aware and finally to be obedient. The data source used consists of library materials both in the form of documents, books, and scientific writings and other relevant information. Data collection is carried out with literature study techniques, with the approval of the principle of relevance and novelty of the information collected. The analysis is content analysis (classification, interpretation and inference findings).
\end{abstract}

Keywords: Waqf, Legal Knowledge, Legal Awareness, Legal Obedience. 
Abstrak: Hukum wakaf dapat dikategorikan sebagai the living law. Sekalipun demikian, terdapat usaha-usaha untuk mengaktualisasikan potensi wakaf. Hal ini mengisyaratkan, bahwa hukum- yang-hidup tidak selalu tegak secara teoritis. Sehubungan dengan itu, masalah ini dapat diidentifikasi sebagai masalah penegakan-hukum-perwakafan. Maka masalah ini dirumuskan ke dalam pertanyaan: Bagaimana kepatuhan hukum masyarakat terhadap Undang-undang Wakaf? Penelitian ini difokuskan pada unsur-unsur mengenai pengetahuan masyarakat (legal knowledge), kesadaran masyarakat (legal awareness), dan kepatuhan masyarakat (legal obidience) terhadap UU Wakaf. Dengan asumsi syariah merupakan hukum kodrat (natural law), sehingga sifatnya kekal dan tidak berubah. Sekalipun demikian, dalam kasus wakaf, syariah tidak menentukan secara tegas mengenai wakaf. Ketentuan hukum wakaf diperoleh melalui ushul fiqh, dengan pola penalaran deduktif analogis. Selebihnya, ketentuan mengenai mekanisme wakaf diperoleh berdasarkan preferensi manusia mengenai kebaikan umum (public good). Hukum wakaf lebih didasarkan pada ruh al-hukm, semangat ajaran, dan maqashid al-syariah. Sehingga wakaf lebih memungkinkan untuk dikembangkan menjadi lebih responsif terhadap tuntutan dan kebutuhan masyarakat. Peluang penegakan hukum wakaf sangat besar, sehingga pada gilirannya masyarakat patuh terhadap hukum wakaf. Penelitian ini merupakan penelitian deskriptif, yakni menganalisis wakaf sebagai sebuah sistem, sekaligus subsistem dari sistem yang lebih luas. Analisis tersebut, dideskripsikan proses masyarakat dari tahu menjadi sadar dan akhirnya menjadi patuh terhadap hukum wakaf. Sumber data yang digunakan berupa bahan kepustakaan, baik berupa dokumen, buku, dan tulisan-tulisan ilmiah serta informasi lain yang relevan. Pengumpulan data dilakukan dengan teknik studi kepustakaan, dengan menekankan prinsip relevansi dan kebaruan dari informasi yang dihimpun. Adapun analisisnya adalah analisis isi (content-analysis), dengan langkah: klasifikasi data, interpretasi data, serta inferensi temuan.

Kata Kunci: Wakaf, Legal Knowledge, Legal Awareness, Legal Obedience 


\section{Pendahuluan}

Wakaf (waqf atau habs) adalah salah lembaga sosial-keagamaan dalam masyarakat muslim. Keberadaannya tidak hanya didorong oleh keinginan untuk menjalankan substansi ajaran agama, tetapi juga dilaksanakan dengan prosedur yang sejalan dengan syari'at Islam. ${ }^{1}$ Potensinya bagi penguatan keyakinan agama dan perkembangan kehidupan sosial-ekonomi sangat besar. Apabila dikelola secara efektif dan efisien, wakaf tidak hanya akan dapat memenuhi kepentingan ibadah, tetapi juga kemajuan kesejahteraan umum. $^{2}$

Wakaf memiliki sejarah yang panjang pada kebanyakan masyarakat Islam. la menjadi salah lembaga sosial terpenting dalam mengembangkan sifat kedermawanan. Wakaf merupakan bagian-integral dari kegiatan ekonomi ketetanggaan dan kemasyarakatan. Peningkatan kualitas pelayanan dan transparansi pelaksanaannya sejalan dengan efektivitas peranan lembaga-lembaga masyarakat-sipil, yang tidak menghendaki campur tangan pemerintah atas otonomi lembaga wakaf. Selain itu, ia memberikan dukungan nyata bagi masyarakat dalam bidang pendidikan, sosial, dan ekonomi tanpa mendasarkan diri pada pembiayaan pemerintah atau bantuan asing. ${ }^{3}$

Selama berabad-abad, waqf telah menjadi subyek kajian mekanisme hukum. Temuan menunjukkan bahwa wakaf dapat dikelola dengan baik ketika para pelaku lokal memiliki masukan untuk memfungsikannya. Masa depan kebangkitan lembaga ini akan bergantung pada peran para pelaku lokal yang dilengkapi kemampuan untuk memberdayakan wakaf. Terdapat banyak contoh mengenai adaptasi kerangka pengaturan dan manajemen modern terhadap wakaf.

Pendekatan-pendekatan inovatif terhadap wakaf tanah, termasuk tanah negara, mengarahkan sebagian besar bagian tanah-tanah ini untuk lebih mudah diakses oleh masyarakat luas. Terdapat aturan khusus dalam Syariat mengenai "tanah mati" (mawat), ${ }^{4}$ yang tidak dimiliki atau dimanfaatkan oleh seseorang atau sekelompok orang, karena pada prinsipnya tanah tidak boleh terbengkalai. Contohnya, kasus tanah di Madinah, Saudi Arabia, yang memungkinkan masyarakat untuk memanfaatkan tanah yang dipandang sebagai tanah-mati (mawat).

Di Indonesia, pranata wakaf telah melekat dalam tradisi masyarakat Muslim. Bahkan, usia pranata ini setua usia sejarah Islam di negeri ini. Pembuktian sejarah kedatangan Islam di Indonesia ditentukan berdasarkan temuan arkeologis, seperti kuburan

\footnotetext{
${ }^{1}$ M. A. Tawfiq, The Awqaf in Modern Egypt (The Islamic Quarterly, 1998), 258.

${ }^{2} \mathrm{M}$. Iqbal, Islamic Economic Institutions and the Elimination of Poverty (The Islamic Foundations, 2002), 287.

3 I. E. Ghanem, "Ihya' Tekeyat al Menshawy" . Diambil kembali dari www.islamonline.net: http://Vww.islamonline.net/arabic/economics/2002/11/articleo5/shtml, t.t., 11.

${ }^{4}$ Ahadiah Shofiana, Studi Analisis Terhadap Ihya' Al-Mawat Dalam Figh Madzhab Al-Maliki, tidak dipublikasikan. (Semarang: IAIN Walisongo, 2004).
} 
atau reruntuhan mesjid. Sampai sekarang, kuburan dan mesjid menjadi obyek peruntukan wakaf sampai sekarang.

Perkembangan pranata wakaf mengalami perubahan. la melintasi masa kesultanan, masa kolonial, dan masa kemerdekaan. Pada masa kesultanan, ia diatur oleh adat kebiasaan masyarakat lokal. Pada masa kolonial, terdapat berbagai pandangan mengenai pengaturan wakaf. Pada masa kemerdekaan, diatur oleh berbagai peraturan-perundangan. Akan tetapi, hubungan vertikal dan horizontal antar peraturan-perundangan tidak dipersoalkan. Pada masa reformasi, ketika tuntutan identitas kedaerahan dan keagamaan semakin kuat, pembentukan Undang-undang Wakaf dilakukan oleh Pemerintah (Undang-undang Nomor 41 Tahun 2004). Berdasarkan pertimbangan sosiohistoris, yuridis, dan filosofis, maka wakaf telah merupakan salah satu hukum yang hidup (living law) dalam masyarakat muslim di Indonesia.

Bagi masyarakat muslim di Indonesia, wakaf selaras dengan cita-cita hukum, berakar dalam kehidupan sosial, dan dikukuhkan secara yuridis. ${ }^{5}$ Meskipun telah memenuhi kriteria sebagai sebuah hukum yang hidup, namun tidak berarti ia serta-merta menjadi sebuah "hukum yang tegak". Penegakan hukum (law enforcement) terhadap ketentuan-ketentuan yang tertuang di dalam Undang-undang Wakaf, hanya akan dapat dilakukan jika undang-undang tersebut sistematis, baik secara vertikal maupun horizontal, dalam tata hukum di Indonesia, ditegakkan oleh penegak hukum yang bersih dan berwibawa, serta didukung oleh kepatuhan hukum dari para pendukung dalam melaksanakan peraturan yang tertuang dalam undang-undang tersebut. Tanpa kondisi itu, hukum tersebut tidak akan tegak, tetapi malah mengarah pada sleeping ordonantie atau bahkan dode regel. Berdasarkan keterangan tersebut, maka permasalahan mengenai kepatuhan hukum masyarakat terhadap Undang-undang wakaf menjadi menarik.

\section{Metodologi}

Penelitian ini dimaksudkan untuk mendeskripsikan masalah penegakan hukum perwakafan di Indonesia. Berdasarkan maksudnya, penelitian ini termasuk ke dalam penelitian deskriptif (descriptive research). Dengan metode ini, penegakan hukum perwakafan digambarkan sebagai sebuah situasi atau kejadian berdasarkan proses akumulasi dari jenis data terkait. ${ }^{6}$ Data yang berhubungan dengan masalah penegakan hukum perwakafan dihimpun secara sistematis dengan senantiasa mempertimbangkan aktualitas dan akurasinya. ${ }^{7}$ Penegakan hukum perwakafan diharapkan dapat disajikan dalam suatu gambaran yang relatif baru. ${ }^{8}$ Jadi, penelitian ini berusaha menghimpun dan meng-

\footnotetext{
${ }^{5}$ Boedi Abdullah, "Hukum Wakaf Benda Bergerak (Uang) Menurut Fatwa Ulama dan UndangUndang Nomor 41 Tahun 2014 Tentang Wakaf," Asy-Syari'ah 20, no. 1 (Agustus 2018): hlm. 2.

${ }^{6}$ M. Nazir, Metode Penelitian (Jakarta: Ghalia Indonesia, 1983), hlm. 51.

${ }^{7}$ S. Suryadibrata, Metode Penelitian (Jakarta: Rajawali Press, 1991), hlm. 18.

${ }^{8}$ K. W. Eckhardt, Social Research Methods: Perspective, Theory, and Analysis (New York: Random House Inc., 1977).
} 
akumulasikan data secara sistematis, faktual, dan akurat dalam rangka menemukan dan menyajikan informasi yang baru dan mendalam mengenai penegakan hukum perwakafan dalam sistem hukum nasional di Indonesia.

\section{Hasil Penelitian dan Pembahasan Wakaf dalam Syariah}

Syari'at Islam menetapkan dua kategori ajaran keberagamaan: Pertama, 'ibadah, ajaran-ajaran tentang hubungan antara manusia dengan Allah, dan Kedua, mu'amalah, ajaran-ajaran mengenai hubungan antar sesama manusia. Wakaf termasuk ke dalam mu'amalah karena mengajarkan umat Islam untuk berbuat dermawan. Sebagai institusi sosial, wakaf terikat oleh norma dan tujuan sosial yang penting bagi peningkatan kehidupan umat.

Pada umumnya, praktek wakaf dimulai sejak masa sahabat, 'Umar bin Khaththab r.a. tentang lahan di Khaybar. Sekalipun demikian, dikisahkan pula bahwa praktek wakaf dimulai sejak pendirian Masjid Quba pada masa Rasulullah saw. Dewasa ini, dikemukakan bahwa Nabi Muhammad saw. Hanya melanjutkan tradisi yang baik pada masa pra-Islam. Tradisi melakukan kebaikan untuk kepentingan umum telah dikenal sejak masa Fir'aun di Mesir. Kelompok kaya merelakan sebagian tanah pertanian untuk digarap oleh kelompok miskin dan hasilnya dimanfaatkan untuk berbagai kepentingan publik. Ensiklopedia Grolyier International menyebutkan bahwa tradisi ini serupa dengan kegiatan filantrofis yang telah dikenal oleh masyarakat Yunani dan Romawi. Manfaat sosial dari tradisi demikian masih dirasakan dan diakses oleh masyarakat umum hingga sekarang, terutama dalam wujud universitas, perpustakaan, musium, dan laboratorium.

Tradisi ini dilanjutkan dan dikembangkan pada Masa Muslim. Hasil kebiasaan wakaf tidak hanya dimanfaatkan dalam pembanngunan sarana-pasarana pendidikan, tetapi juga untuk pembiayaan pendidikan (beasiswa, pengembangan sains dan teknologi). Dengan demikian, wakaf merupakan tradisi kemanusiaan yang telah, terus, dan akan tetap berkembang. Hukum perwakafan perlu difahami baik dalam arti "aturan dalam yang tertuang dalam kitab hukum" (law in book) maupun dalam arti "aturan dalam tindakan" (law in action), pelaksanaan hukum perwakafan dalam perspektif sosiologis.

\section{Wakaf sebagai Ibadah Sosial}

Ibadah sosial adalah jenis ibadah yang lebih berorientasi pada "kebaikan umum" (public good). Wakaf masuk kategori ibadah sosial. Doktrin wakaf disandarkan pada hadits Rasulallah saw, seperti yang diriwayatkan Muslim 9 "Apabila anak Adam meninggal maka terputuslah semua amalnya kecuali tiga perkara: shadaqoh jariyah, ilmu yang bermanfaat dan anak soleh yang mendoakannya". Makna shadaqah jariyah (H.R Muslim).

\footnotetext{
${ }^{9}$ Imam Muslim, Shahih Muslim, Juz II (Bandung: Dahlan, T.th), 14.
} 
Menurut Imam Nawawi dalam Syarh Shahih Muslim, adalah wakaf, yaitu menahan harta dan membagikan (memanfaatkan) hasilnya. ${ }^{10}$ Wakaf dalam pengertian sebagai shadaqah merupakan wujud kebajikan pribadi karena setara dengan penguasaan atas pengetahuan yang bermanfaat serta pemilikan anak yang saleh karena selalu mendoakannya, sekaligus memiliki nilai ibadah sosial karena bermanfaat bagi kesejahteraan umum.

Fakta sejarah membuktikan bahwa institusi wakaf diorientasikan untuk kepentingan umum. 'Umar ibn Khaththab telah memberikan kebunnya di Khaybar dan mendistribusikan hasilnya untuk memenuhi keperluan kelompok masyarakat miskin, seperti anak yatim dan budak-belian. Wakaf ini diorientasikan untuk mengurangi tingkat ketimpangan sosial ekonomi.

Wakaf tidak bersumber dari sektor penerimaan negara, seperti pajak. Wakaf pun tidak bersumber dari penerimaan sektor swasta seperti pertanggungjawaban sosial swasta (corporate social responsibilities). Wakaf bersumber dari penerimaan sektor masyarakat (civil society). Dengan demikian, wakaf merupakan sarana yang sangat fleksibel dan dinamis dalam pembiayaan kepentingan umum. Wakaf dapat dimanfaatkan untuk "kepentingan umum" (public good) dalam bentuk kesejahteraan, kesehatan, pendidikan, dan sebagainya. Dalam wakaf, kelompok penerima manfaatnya pun bersifat umum. Pengelolaan lembaga wakaf telah memberikan kontribusi yang sangat besar bagi kesejahteraan masyarakat Muslim secara khusus dan peradaban manusia pada umumnya.

\section{Keutamaan Wakaf}

Keutamaan wakaf ${ }^{11}$ didasarkan pada berbagai dalil yang bersumber dari ayat AlQuran dan Hadits. Pertama, Surat Ali Imran ayat 92 menyebutkan bahwa kesempurnaan ibadah merupakan fungsi dari pemberian harta, bahkan sekalipun dicintai, oleh pemberinya. Kedua, Surat al-Baqarah ayat 261 yang menjanjikan bahwa perbuatan menafkahkan harta akan mendapatkan balasan dengan balasan yang berlipat ganda. Ketiga, Hadits dari Abu Hurairah r.a. meriwayatkan bahwa salah pahala yang tidak akan pernah putus dan melintas hingga setelah hari kematian anak Adam adalah shadaqah jariyah.

Instritusi wakaf merujuk pada konsep shadaqah jariyah seperti yang tertsurat pada dalil-dalil tersebut. Syaikh Abdullah Ali Bassam menyatakan bahwa wakaf adalah sedekah yang paling mulia karena senantiasa memberikan andil bagi kemaslahatan umum dan peradaban manusia. Penerima manfaat wakaf (mauquf alaih) akan sangat terbantu karena adanya institusi wakaf ini. Pewakaf (wakif) akan selalu mendapatkan pahala yang tidak akan terputus bahkan hingga kematian menjemputnya. Barang yang diwakafkan akan tetap utuh sampai kapanpun dan terus berakumulasi serta terus memberikan andil bagi wakif, maukuf alaih, dan masyarakat secara umum.

${ }^{10}$ Wahbah Az-Zuhaili, Fiqih Islam wa Adillatuhu 10, Penerjemah Abdul Hayyie Al-Khatami (Jakarta: Gema Insani, 2011), 271.

${ }^{11}$ J. S. Praja, Perwakafan di Indonesia: Sejarah Pemikiran Hukum dan Perkembangannya (Bandung: Yayasan Piara, 1993). 


\section{Wakaf dalam Lintasan Sejarah Muslim}

Wakaf sudah menjadi tradisi masyarakat Arab kuno di Makkah. Ka'bah berfungsi sebagai sarana peribadatan bagi masyarakat lokal seperti dinyatakan dalam Al-Quran, Q.S. Ali Imran ayat 96. Ka'bah menjadi institusi wakaf pertama yang dimanfaatkan untuk kepentingan sosial keagamaan pada masa itu. Rasulullah Muhammad saw. meneruskan tradisi wakaf. Pembangunan masjid Ouba' pada hijrah dari Mekkah ke Madinah. Pendirian Masjid Nabawi merupakan bukti lain bahwa tradisi wakaf dimulai sejak masa Nabi. Nabi telah melembagakan wakaf dengan memberikan tanah untuk sarana peribadatan umat Islam. Wakaf menjadi salah satu institusi sosial dalam masyarat Muslim. Dalam konteks ini, wakaf pun menjadi sunnah, sehingga dari generasi ke generasi masyarakat Muslim di seluruh dunia meneladani perbuatan ini dan menetapkannya sebagai ibadah.

\section{Wakaf untuk Peningkatan Peradaban Umat}

Masjid menjadi harta wakaf sejak masa awal Islam. Fungsinya tidak hanya sebagai sarana ibadah. Masjid pun dimanfaatkan sebagai sarana pendidikan dan pengajaran, halaqah atau lingkar-studi.

Halaqah-halaqah ini pada mulanya hanya mengajarkan cara membaca dan menulis al-Qur'an. Dalam perkembangan berikutnya, halaqah ini mengajarkan pengetahuan lain, terutama matematika sebagai alat bantu dalam pelaksanaan ibadah shalat. Masjid pun melahirkan banyak madrasah dan para ilmuwan. Keberhasilan Muslim dalam mengelola harta wakaf secara efektif dan efisien menjadi tonggak sejarah kemajuan peradaban Muslim.

Sekolah, perpustakaan, pusat studi, dan universitas yang berbasis wakaf lahir di berbagai kota besar Muslim saat itu, seperti di Damaskus, Baghdad, Kairo, dan Asfahan. Harta wakaf yang terus bertambah tidak hanya memfasilitasi sarana prasarana pendidikan tetapi juga dimanfaatkan untuk pembiayaan pendidiksn, seperti beasiswa, gaji guru, penelitian dan pengembangan ilmu, penyediaan sumber dan media pembelajaran, termasuk perpustakan dan alat-alat laboratorium. Manfaat wakaf pun digunakan untuk memenuhi kepentingan terkait kegiatan ibadah dan pendidikan serta infrastruktur terkait kegiatan tadi, prasarana lalu lintas, taman kota, dan pasar.

Wakaf tidak hanya mampu mengurangi kesenjangan sosial antara kelompok kaya dengan kelompok miskin, tetapi juga mampu meningkatkan taraf hidup rerata anggota masyarakat. Fungsi kesejahteraan sosial dai institusi wakaf inidimanfaatkan antara lain: (1) untuk fasilitas umum, seperti wakaf sumur, mata air, jalan, dan jembatan untuk melayani keperluan jamaah haji dan kafilah di wilayah Muslim. (2) untuk bantuan pendidikan, kesehatan, dan peningkatan daya-beli masyarakat miskin, seperti beasiswa, pengobatan, pelatihan kerja, dan bantuan permodalan. (3) untuk pelestarian lingkungan hidup berupa penciptaan taman-taman kota dan penngendalian ruang hijau dalam 
memelihara keseimbangan ekosistem di sekitar. Mislnya wakaf ruang terbuka hijau, sungai, saluran air, bahkan burung-burung (merpati) di Masjidil Haram, Makkah. Dallildalil tentang Wakaf bersifat umum. Mekanisme pengaturannya diserahkan kepada para hasil ijtihad ulama dari waktu ke waktu.

\section{Aspek Yuridis Wakaf}

Wakaf merupakan pranata sosial yang hidup dan berkembang dalam masyarakat Muslim di Indonesia. Islam datang ditandai dengan adanya "kuburan", Islam membentuk komunitas ditandai denngan adanya "reruntuhan masjid", dan Islam menjadi sebuah kekuatan politik diawali dengan adanya "kesultanan". ${ }^{12}$ Kuburan, mesjid, dan keraton Muslim berhubungan erat dengan harta wakaf. Muslim di Indonesia memiliki budaya hukum (legal culture) atau sikap dan nilai serta tingkah laku bersama tersendiri mengenai perwakafan.

Pelaksanaan wakaf didasarkan atas ketentuan-ketentuan Fiqh yang dominan, Madzhab Syafi'iyah. Wakaf adalah memberikan sebagian harta sambil menghilangkan hak kepemilikan dari pemilik (wakif) untuk dimanfaatkan pada sesuatu yang dibolehkan. Pada masa ini, wakaf dikategorikan ibadah mahdhah. Wakaf difahami sebagai bagian dari akhlak mulia. Benda wakaf diperuntukkan untuk kepentingan pembangunan fisik, seperti masjid, mushalla, pesantren, perkuburan, yayasan, dan dana bantuan untuk kepentingan konsumtif. Dengan demikian, budaya wakaf di Indonesia masih bersandar pada kebiasaan-kebiasaan keagamaan, seperti yang berbasis tradisi lisan dan atas dasar prinsip rasa saling percaya.

Pada masa kemerdekaan, ketika Indonesia dinyatakan sebagai negara hukum, praktik wakaf tradisional ini telah melahirkan sejumlah persoalan ketidakkepastian hukum harta wakaf dan persengketaan sosial karena tidak adanya validitas hukum atas benda wakaf. Peraturan perundang-undangan yang selama ini mengatur masalah perwakafan tersebar dalam berbagai peraturan perundang-undangan. Beberapa diantaranya Undang-undang Nomor 5 Tahun 1960 tentang Undang-undang Pokok Agraria, Peraturan Pemerintah Nomor 28 Tahun 1977 tentang Perwakafan Tanah Milik, Peraturan Menteri Agama Republik Indonesia Nomor 1 Tahun 1978 tentang Pelaksanaan PP No. 28 Tahun 1977, Peraturan Direktur Jenderal Bimbingan Masyarkat Islam Departemen Agama Republik Indonesia Nomor Kep/D/75/1978, Instruksi Presiden Republik Indonesia Nomor 1 Tahun 1991 tentang Kompilasi Hukum Islam (KHI). Sekalipun demikian, landasan yuridis perwakafan yang dibuat setelah kemerdekaan dianggap masih belum memadai. Salah satu dari produk reformasi hukum adalah terbitnya Undang-undang Republik Indonesia Nomor 41 Tahun 2004 tentang Wakaf.

12 Daniel S Lev, Islamic Courts In Indonesia, A Study In The Political Basis of Legal Institution, Alih Bahasa oleh Zaeni Ahmad Noeh, Peradilan Agama Islam di Indonesia Suatu Studi Tentang Landasan Politik Lembaga-Lembaga Hukum (Jakarta: Intermasa, 1986). 


\section{Perundang-undangan Wakaf}

Alasan yang mendorong pemberlakuan Undang-undang Nomor 41 Tahun 2004 tentang Wakaf adalah fungsi ketertiban dan kesehateraan dari praktek perwakafan di Indonesia. Praktek perwakafan yang dilaksanakan masyarakat Indonesia selama ini belum terlaksana secara tertib. Harta wakaf tidak terpelihara dengan secara utuh. Kolonialisasi dan nasionalisasi serta pihak lain yang tidak bertanggung jawab menjadi pengurangan bagi jumlah harta wakaf Muslim. Undang-undang ini diorentasikan menciptakan substansi hukum (legal substance) yang integral dan komprehensif tentang wakaf agar ketidakpatian hukum yang menjadi kendala dalam pelaksanaan wakaf selama ini dapat teratasi.

Terdapat beberapa pembaruan dalam Undang-undang Nomor 41 tentang Wakaf dibandingkan peraturan perundang-undangan sebelumnya, terutama Peraturan Pemerintah No. 28 Tahun 1977 tentang Perwakafan Tanah Milik. Undang-undang Nomor ini tidak hanya mengatur perwakafan tanah milik, tetapi perwakafan semua benda baik benda bergerak maupun benda tidak bergerak. Undang-undang inipun diorientasikan mem melakukan pembaruan dalam struktur hukum (legal structure) atau berbagai pihak yang terkait dengan sistem pengelolaan wakaf dan budaya hukum (legal culture) atau pengetahuan, sikap, dan perbuatan hukum masyarakat.

Tulisan ini berhubungan dengan pembaruan budaya hukum masyarakat dalam perwakafan karena pembaruan substansi hukum dan peningkatan profesionalitas struktur hukum tidak akan efektif jika didukung oleh budaya hukum yang kondusif dalam praktek perwakafan. Yang dimaksud dengan budaya hukum, menurut Lawrence M. Friedman, ${ }^{13}$

"... people's attitudes toward law and legal system-their beliefs, values, ideas, and expectations. The legal culture, in other words, is the climate of social thought and social force which determines how law is used, avoided, or abused. Without legal culture, the legal system is inert-a dead fish lying in a basket, not a living fish swimming in its sea".

Budaya hukum adalah sikap-sikap dan nilai-nilai tentang hukum dan sistem hukum, termasuk sikap-sikap dan nilai-nilai yang memberikan pengaruh baik positif maupun negatif kepada tingkah laku hukum.

Pengetahuan masyarakat tentang substansi Undang-undang Nomor 41 Tahun 2004 tentang Wakaf masih lemah. ${ }^{14}$ Masyarakat Muslim masih memahami wakaf sebagai bagian dari ibadah mahdhah, yang bersifat personal didasarkan pada prinsip rasa saling percaya dan pelaksanaannya tidak perlu diadministrasikan secara tertulis. Bahkan,

\footnotetext{
${ }^{13}$ Lawrence M. Friedman, Legal System, The: A Social Science Perspective (Russell: Sage Foundation, 1975), 6 .

${ }^{14}$ Dewi Sri Indriati, "Urgensi Wakaf Produktif Dalam Pembangunan Ekonomi Masyarakat" Vol. 15, no. 2 (2017): 103.
} 
beberapa kalangan masyarakat Muslim menilai pengadministrasian wakaf dapat menimbulkan riya' yang bisa mengurangi makna ibadahnya. Pengetahuan tentang konsep wakaf ini melahirkan rendahnya "kesadaran hukum" (legal awareness) akan urgensi pasal-pasal yang dituangkan dalam Undang-undang Nomor 41 tahun 2004 tentang Wakaf. Akhirnya, sejalan dengan rendahnya pengetahuan dan kesadaran masyarakat Muslim tersebut, ketentuan-ketentuan yang dituliskan dalam Undang-undang melahirkan rendahnya tingkat kepatuhan hukum (legal obedience) masyarakat terhadap undang-undang Nomor 41 tahun 2004 tentang Wakaf.

\section{Simpulan}

Wakaf merupakan salah satu institusi sosial yang penting dalam masyarakat Muslim. Sebagai sebuah institusi sosial, memperlihatkan norma agama, perilaku keagamaan, dan melahirkan tujuan sosial keagamaan. Wakaf telah ada sejak masa kesultanan, masa kolonial, dan masa kemerdekaan. Karena alasan politik, kaidah-kaidah fikih wakaf ditransformasikan ke dalam sistem hukum nasional dengan lahirnya Undangundang Nomor 41 Tahun 2004 tentang Wakaf.

Undang-undang ini dimaksudkan untuk mengubah sistem hukum perwakafan di Indonesia, karena menyangkut perubahan substansi, struktur, dan kultur hukumnya. Masalah krusial dalam setiap pelaksanaan Undang-undang adalah kesenjangan antara law in book dengan law in action. Dengan demikian, cara pandang terhadap undangundang tersebut tidak serta-merta dapat dipatuhi oleh oleh masyarakat Indonesia. Pelaksanaan Undang-undang merupakan fungsi dari sistematisasi perangkat hukum, baik secara vertikal maupun horisontal, kinerja aparat penegak hukum, dan kepatuhan hukum. Indikator efektif tidaknya undang-undang tampak dari tingkat kepatuhan masyarakat atas semua isi undang-undang tersebut.

Budaya hukum (legal culture) masyarakat Indonesia terhadap Undang-undang Nomor 41 Tahun 2004 tentang Wakaf merupakan fungsi dari pengetahuan hukum masyarakat (legal knowledge), kesadaran hukum (legal awareness), dan kepatuhan hukum (legal obedience) masyarakat Indonesia terhadap Undang-undang Nomor 41 Tahun 2004 tentang Wakaf. Untuk menguatkan budaya hukum wakaf masyarakat, maka perlu penyuluhan hukum, penyadaran hukum, dan penegakan hukum wakaf. 


\section{DAFTAR PUSTAKA}

Abdullah, Boedi. "Hukum Wakaf Benda Bergerak (Uang) Menurut Fatwa Ulama dan Undang-Undang Nomor 41 Tahun 2014 Tentang Wakaf." Asy-Syari'ah 20, no. 1 (Agustus 2018): 1-14.

Az-Zuhaili, Wahbah. Fiqih Islam wa Adillatuhu 10, Penerjemah Abdul Hayyie Al-Khatami. Jakarta: Gema Insani, 2011.

Eckhardt, K. W. Social Research Methods: Perspective, Theory, and Analysis. New York: Random House Inc., 1977.

Friedman, Lawrence M. Legal System, The: A Social Science Perspective. Russell: Sage Foundation, 1975 .

Ghanem, I. E. "Ihya' Tekeyat al Menshawy" . Diambil kembali dari www.islamonline.net: http://vww.is/amonline.net/arabic/economics/2002/11/articleo5/shtml, t.t.

Indriati, Dewi Sri. "Urgensi Wakaf Produktif Dalam Pembangunan Ekonomi Masyarakat" Vol. 15, no. 2 (2017): 94-114.

Iqbal, M. Islamic Economic Institutions and the Elimination of Poverty. The Islamic Foundations, 2002.

Lev, Daniel S. Islamic Courts In Indonesia, A Study In The Political Basis of Legal Institution, Alih Bahasa oleh Zaeni Ahmad Noeh, Peradilan Agama Islam di Indonesia Suatu Studi Tentang Landasan Politik Lembaga-Lembaga Hukum. Jakarta: Intermasa, 1986.

Muslim, Imam. Shahih Muslim. Juz II. Bandung: Dahlan, T.th.

Nazir, M. Metode Penelitian. Jakarta: Ghalia Indonesia, 1983.

Praja, J. S. Perwakafan di Indonesia: Sejarah Pemikiran Hukum dan Perkembangannya. Bandung: Yayasan Piara, 1993.

Shofiana, Ahadiah. Studi Analisis Terhadap Ihya' Al-Mawat Dalam Fiqh Madzhab AlMaliki. Tidak dipublikasikan. Semarang: IAIN Walisongo, 2004.

Suryadibrata, S. Metode Penelitian. Jakarta: Rajawali Press, 1991.

Tawfiq, M. A. The Awqaf in Modern Egypt. The Islamic Quarterly, 1998. 
158 | Asy-Syari'ah Vol. 22 No.1, Juni 2020 
Asy-Syari'ah (P-ISSN: 2086-9029 E-ISSN: 2654-5675) is a periodical scientific journal that publishes various results of studies and research, literature review, and other scientific works whose scope covers the field of Islamic law/sharia, law and society in monodisciplinary, interdisciplinary, and multidisciplinary manners. The journal aims to expand and create innovative concepts, theories, paradigms, perspectives and methodologies in the above said scope. The Journal is published twice a year (june and december) by Faculty of Shariah and Law, Sunan Gunung Djati State Islamic University Bandung in collaboration with Asosiasi Sarjana Syariah Indonesia (ASSYI).

\section{EDITORIAL OFFICE:}

Fakultas Syariah dan Hukum UIN Sunan Gunung Djati Bandung J1. Raya A.H. Nasution No. 105 Cibiru Kota Bandung, 40614

Tlp/Fax: +022-7802278 Faks. 022-7802278

Website http://journal.uinsgd.ac.id/index.php/asy-syariah/index

E-mail: Jurnalasy-syariah@uinsgd.ac.id 